\title{
PEMBUATAN BRIKET DARI KULIT KAKAO MENGGUNAKAN PEREKAT KULIT UBI KAYU
}

\section{COCOA SKIN BRIQUETTES MAKING BY USING CASSAVA SKIN ADHESIVE}

\author{
Rosta Natalia Sinaga, Rosdanelli Hasibuan \\ Departemen Teknik Kimia, Fakultas Teknik, Universitas Sumatera Utara, \\ Jalan Almamater, Kampus USU Medan, 20155, Indonesia \\ Email: rostanatalia@gmail.com
}

\begin{abstract}
Abstrak
Penelitian ini bertujuan untuk mengetahui pengaruh variasi suhu pengarangan, waktu pengarangan dan variasi perekat terhadap karakteristik arang dari kulit kakao menggunakan perekat kulit ubi kayu. Pembuatan briket biasanya dibuat dengan bantuan perekat. Perekat berfungsi merekatkan arang satu sama lain sehingga terbentuk briket yang kuat dan kompak. Beberapa variabel yang mempengaruhi kualitas briket antara lain bahan baku, proses pengarangan, dan tekanan pengempaan. Penelitian pembuatan briket ini menggunakan arang kulit kakao sebagai bahan baku dengan perekat kulit ubi kayu. Semua variabel secara tidak langsung mempengaruhi kandungan fixed carbon briket yang sangat menentukan nilai kalor briket. Nilai kalor briket adalah faktor terpenting penentuan kualitas briket. Pada penelitian ini nilai kalor briket tertinggi sebesar $4.375 \mathrm{kal} / \mathrm{g}$, tekanan pengempaan $85 \mathrm{~kg} / \mathrm{cm}^{2}$ dan konsentrasi perekat $20 \%$ dari berat bahan baku dengan ukuran partikel 100 mesh. Nilai kalor briket ini masih sangat rendah dan tidak sesuai dengan standar briket Indonesia. Kulit ubi kayu tidak baik digunakan sebagai perekat pada briket karena berdasarkan uji tekan, briket yang dihasilkan pada setiap variasi konsentrasi perekat, proses pengarangan, dan tekanan pengempaan memiliki struktur yang lunak, tidak kuat, dan mudah hancur.
\end{abstract}

Kata kunci: briket, kulit ubi kayu, kulit kakao, proses pengarangan,nilai kalor

\begin{abstract}
This study aims to determine the effect of temperature variation carbonization, carbonization time and adhesive variation to charcoal characteristics of cocoa skin using cassava skin adhesive. Briquette is usually made using binder. Binder can embed charcoal each other to form strong and compact briquettes. Some other variables beside binder that influence the quality of briquettes include raw material, compacting presseure and carbonization process. This research used cocoa leather as raw material with cassava skin leaves as binder. All variables affect the content of fixed carbon of the briquettes that influence the caloricvalue of the briquettes. The caloricvalue is the most important factor for determining the quality of the briquettes. In this research, the highest caloricvalue of the briquettes was $4.375 \mathrm{cal} / \mathrm{g}$. It was achieved when cocoa leather were carbonized by method 1 with compaction pressure of $85 \mathrm{~kg} / \mathrm{cm}^{2}$ and binderconcentration of $15 \%$ where as raw material with particle size of 100 mesh. The caloricvalue of the briquettes was still very low and did not meet the qualification of Indonesian standard for briquettes. Based on the strength test, cassava skin leaves couldn't be used as briquette's binder. The produced briquettes that used cassava skin leaves as binder had soft structure and easily destroyed.
\end{abstract}

Keywords : briquettes, cassava skin, cocoa leather, carbonization process, caloric value

\section{Pendahuluan}

Kebutuhan dan konsumsi energi semakin meningkat sejalan dengan bertambahnya populasi manusia dan meningkatnya perekonomian masyarakat. Di Indonesia kebutuhan dan konsumsi energy terfokus kepada penggunaan bahan bakar minyak yang cadangannya semakin menipis, sedangkan pada sisi lain terdapat sejumlah energi biomassa yang kuantitasnya cukup melimpah namun belum dioptimalkan penggunaannya.

Minyak merupakan sumber energi tak terbarukan yang populer sebagai sumber utama bahan bakar. Hal ini berarti produksi minyak pada awalnya terus meningkat yang kemudian akan sampai pada puncaknya dan mulai menurun secara bertahap sesuai dengan persediaan minyak fosil yang semakin sedikit. Jadi tidak dapat disangkal bahwa minyak suatu saat akan habis akibat pemakaian secara terus menerus dan akan meningkat penggunaannya

Biomassa secara umum lebih dikenal sebagai bahan kering material organik atau bahan yang tersisa setelah suatu tanaman atau material organik dihilangkan kadar airnya. Limbah biomassa dan sampah biasa, menjadi salah satu pilihan sumber 
energi alternatif. Contoh nyata pemanfaatan energi biomassa yang berasal dari produk limbah aktivitas kehutanan dan perkebunan dan telah banyak dilaksanakan yaitu kayu bakar dan arang. [9]

Briket merupakan material yang mudah terbakar yang terbentuk dari proses pengempaan atau pemampatan material menjadi bentuk padatan dan digunakan sebagai bahan bakar. Briket yang dihasilkan harus memiliki sifat yang kuat dan saling merekat satu sama lain sehingga briket tidak mudah hancur [21]. Berdasarkan beberapa penelitian yang telah dilakukan sebelumnya, maka peneliti tertarik untuk mengembangkan bahan alternatif pengganti minyak tanah yang berasal dari bahan bakar fosil sebagai energi terbarukan dan mengatasi beberapa masalah krisis energi maka dikembangkan penelitian pembuatan briket dari kulit kakao menggunakan perekat kulit ubi kayu.

Penelitian ini bertujuan untuk mengetahui pengaruh variasi waktu pengarangan, pengaruh variasi suhu pengarangan dan variasi perekat terhadap karakteristik dari kulit kakao menggunakan perekat kulit ubi kayu.

\section{Teori}

Kakao merupakan salah satu komoditas andalan perkebunan yang peranannya cukup penting bagi perekonomian nasional, Sulawesi Selatan merupakan salah satu sentra penghasil kakao terbesar di Indonesia. Limbah sortiran biji kakao merupakan biomassa yang memiliki komposisi zat yang dapat dimanfaatkan sebagai energi pembuatan briket [8]. Dalam pembuatan briket diperlukan sebuah perekat (binder). Bahan perekat yang dapat digunakan yaitu molase, pati tapioka (kanji) dan tanah liat. Selain perekat pati tapioka, juga terdapat bahan tambahan lain yaitu kapur dengan jenis kapur mati (slake lime) sehingga briket akan memiliki ketahanan terhadap kelembaban dan meningkatkan kekuatan mekanik serta dapat mengikat senyawa biomassa untuk mempercepat atau mempermudah proses pembakaran dan menyerap emisi gas $\mathrm{SO}_{2}$ [10]. Kulit ubi kayu mempunyai komposisi yang terdiri dari karbohidrat dan serat. Persentase kulit ubi kayu yang dihasilkan berkisar antara 8-15\% dari berat umbi yang dikupas, dengan kandungan karbohidrat sekitar 50\% dari kandungan karbohidrat bagian umbinya [11].

Pati atau amilum adalah karbohidrat kompleks yang tidak larut dalam air, berwujud bubuk putih, tawar atau tidak berbau. Pati merupakan bahan utama yang dihasilkan oleh tumbuhan untuk menyimpan kelebihan glukosa (sebagai produk fotosintesis) dalam jangka panjang. Banyak sekali bahan yang biasa digunakan untuk perekat. Asalkan bahan tersebut memiliki sifat lengket atau mampu merekatkan bahan lainnya. Tetapi perlu diingat bahwa bahan yang digunakan sebagai perekat tersebut tidak berbahaya untuk produksi [17]

\section{Metodologi Penelitian Bahan Baku dan Peralatan}

Bahan baku utama dalam penelitian ini adalah kulit kakao, aquadest $\left(\mathrm{H}_{2} \mathrm{O}\right)$ dan kulit ubi kayu sebagai perekat.

Peralatan yang digunakan pada penelitian ini adalah oven, cawan, furnace, kantong plastik, pencetak briket, penjepit tabung, aluminium foil, desikator, pengaduk, wadah plastik, neraca digital, ayakan, termometer, ball mill, bomb calorimeter, selvopulser.

\section{Rancangan Percobaan}

Penelitian ini dilakukan dengan 4 tahap percobaan yaitu tahap persiapan kulit kakao, tahap persiapan kulit ubi kayu, tahap pembuatan briket, dan tahap prosedur analisa (analisa uji eksperimental untuk laju pembakaran, analisa kadar volatile matter, analisa kadar abu, analisa kadar air, analisa kadar fixed carbon, analisa nilai kalor, dan analisa uji tekan)

\section{Prosedur Pembuatan Briket}

Proses pembuatan briket yang dilakukan pada penelitian ini diadopsi dari (Luthfi, dkk., 2012) [15]. Tahap awal dalam pembuatan briket adalah arang kulit kakao hasil pengarangan dihaluskan dengan menggunakan ball mill, serbuk arang diayak dengan ukuran 100 mesh untuk mendapatkan material yang seragam, perekat kulit ubi kayu yang sudah diolah dengan konsentrasi 20 $\%$ dari berat bahan baku dicampurkan ke dalam satu wadah, adonan kulit kakao dicampurkan dengan serbuk arang dari hasil pengayakan sehingga menghasilkan adonan yang lengket, adonan diaduk selama 2 menit agar semua bahan tercampur merata, adonan briket dicetak menggunakan alat cetak briket kemudian ditekan dengan kekuatan $105 \mathrm{~kg} / \mathrm{cm}^{2}$ selama 5 menit, briket yang sudah dicetak di masukkan kedalam oven dan dikeringkan selama 3 jam dengan suhu $105^{\circ} \mathrm{C}$ agar diperoleh briket dengan kadar air yang rendah.

\section{Hasil Dan Pembahasan \\ Pengaruh Suhu Dan Waktu Pengarangan Terhadap Karakteristik Briket}


Briket merupakan salah satu sumber energi alternatif yang penting. Namun sebelum digunakan, terlebih dahulu perlu dilakukan pengujianuntuk mengetahui kualitas briket yang dihasilkan. Analisa kualitas briket yang dihasilkan adalah untuk mengetahui pengaruh variasi suhu pengarangan briket terhadap kadar air, kadar senyawa volatil, kadar abu, kandungan fixed carbon dan nilai kalor briket serta pengaruh variasi waktu pengarangan briket terhadap kadar air, kadar senyawa volatil, kadar abu, kandungan fixed carbon dan nilai kalor briket.

\section{Analisis Kadar Air}

Pada bagian ini, akan dibahas pengaruh waktu pengarangan dan suhu pengarangan terhadap kadar air briket. Waktu pengarangan yang digunakan adalah 30 menit, 60 menit, 90 menit dan 120 menit dengan suhu pengarangan $350^{\circ} \mathrm{C}, 400^{\circ} \mathrm{C}, 450^{\circ} \mathrm{C}$, dan $500^{\circ} \mathrm{C}$ dengan jumlah bahan baku dan perekat yang sama.

\section{Analisis Pengaruh Suhu dan Waktu Pengarangan terhadap Kadar Air}

Pengaruh waktu pengarangan terhadap kadar air dapat dilihat pada Gambar 1.

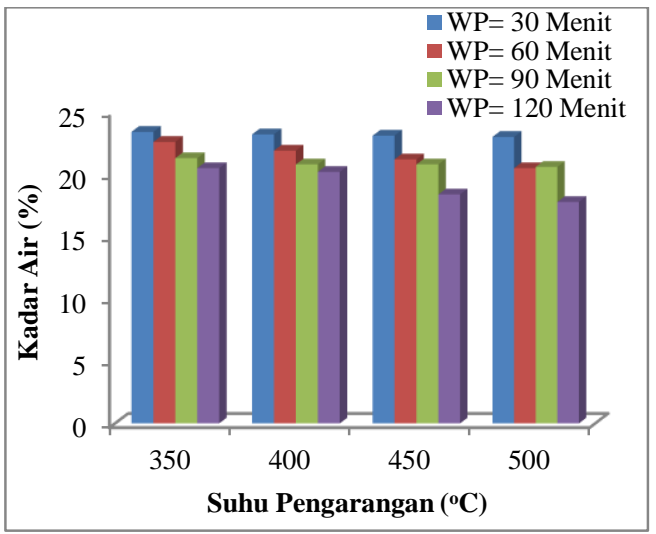

Gambar 1. Pengaruh Suhu dan Waktu Pengarangan terhadap Kadar Air

Gambar 1 memperlihatkan bahwa kadar air briket pada masing-masing perlakuan mengalami penurunan seiring dengan bertambahnya waktu pengarangan,WP yang berarti waktu pengarangan, SP yang berarti suhu pengarangan. Waktu Pengempaan diperoleh bahwa pada waktu pengarangan 120 menit dan pada suhu pengarangan $500^{\circ} \mathrm{C}$ yang memiliki kondisi operasi pengarangan yang baik karena memiliki kadar air yang paling rendah dengan suhu dan waktu pengarangan dibandingkan dengan yang lainnya. Semakin tinggi suhu pengarangan maka kadar air briket yang dihasilkan semakin rendah, hal ini dikarenakan semakin tinggi suhu pengarangan maka air yang terkandung dalam bahan semakin banyak yang menguap. Bila kadar air tinggi, maka semakin panjang waktu yang diperlukan karena uap air yang dihasilkan semakin banyak [14]. Hasil yang didapat telah sesuai dengan hasil penelitian sebelumnya. Secara umum, briket dengan perlakuan waktu pengarangan 120 menit memiliki kandungan air yang kecil dibandingkan dengan sampel lainnya. Hal ini dapat disimpulkan bahwa hasil kadar air yang di dapat cukup baik walaupun belum mencapai standar SNI yang ditentukan.

\section{Analisis Kadar Senyawa Volatil}

Pada bagian ini, akan dibahas pengaruh suhu pengarangan dan waktu pengarangan terhadap kadar senyawa volatil briket.

Analisis Pengaruh Suhu Dan Waktu Pengarangan terhadap Kadar Senyawa Volatil

Selain pengaruh suhu pengarangan, waktu pengarangan juga mempengaruhi kadar senyawa volatil briket. Pengaruh waktu pengarangan terhadap kadar senyawa volatil dapat dilihat pada Gambar 2.

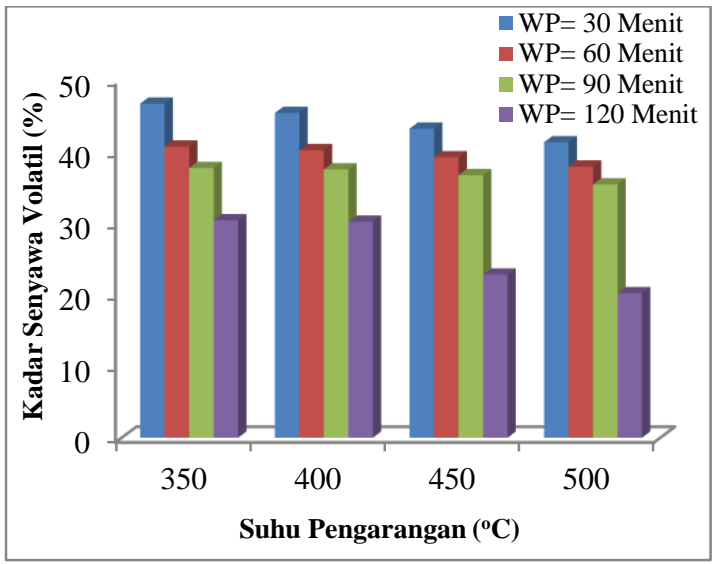

Gambar 2. Pengaruh Suhu dan Waktu Pengarangan terhadap Kadar Senyawa Volatil

Dari Gambar 2 terlihat bahwa kadar senyawa volatil briket pada setiap perlakuan mengalami penurunan seiring dengan bertambahnya suhu pengarangan. Briket dengan waktu pengarangan 120 menit memiliki kadar senyawa volatil yang lebih rendah daripada briket yang diarangkan dengan waktu 30 menit. 
Senyawa volatil merupakan senyawa yang menguap selama proses karbonisasi sehingga senyawa volatil dihitung berdasarkan banyaknya zat yang menguap. Oleh karena itu, semakin banyak zat yang menguap maka semakin besar pula kadar senyawa volatil briket. Hasil yang diperoleh telah sesuai dengan penelitian sebelumnya. Pada penelitian ini kadar senyawa volatil briket yang paling rendah adalah $20,2 \%$ dan dapat dilihat bahwa sangat jauh dari standar. Sehingga dapat disimpulkan bahwa briket yang dihasilkan dari berbagai perlakuan tidak ada yang memenuhi syarat.

\section{Analisis Kadar Abu}

Pada bagian ini, akan dibahas pengaruh suhu pengarangan dan waktu pengarangan terhadap kadar abu briket.

\section{Analisis Pengaruh Suhu Dan Waktu Pengarangan terhadap Kadar Abu}

Berikut ini akan dibahas pengaruh waktu pengarangan terhadap kadar abu briket

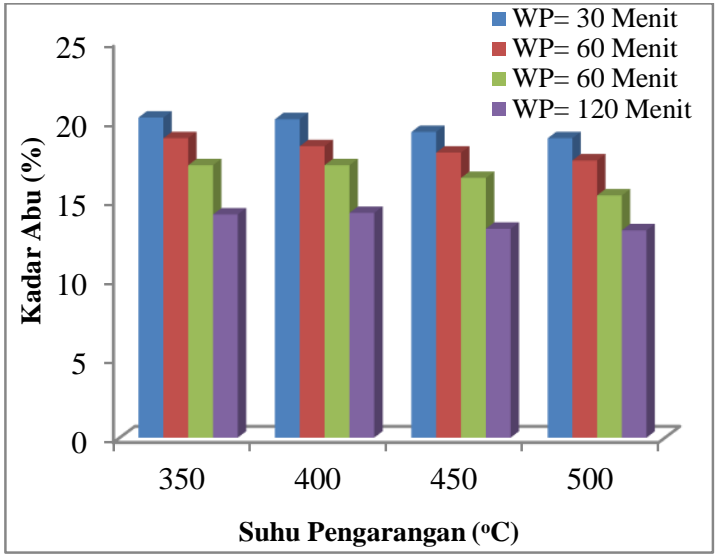

Gambar 3. Pengaruh Suhu dan Waktu Pengarangan terhadap Kadar Abu

Gambar 3 memperlihatkan bahwa kadar air briket pada masing-masing perlakuan mengalami penurunan seiring dengan bertambahnya waktu pengarangan. Kandungan abu pada briket akan menurun seiring dengan kenaikan waktu pengarangan. Hasil yang didapatkan telah sesuai dengan teori. Dari Gambar 3 terlihat bahwa kadar abu briket cukup tinggi. Menurut [15], kualitas kadar abu briket yang sesuai standar adalah 5,51\%. Dilihat dari grafik yang didapat jelas bahwa kadar abu briket tidak memenuhi standar dan sangat jauh dari standar dimana dari data diketahui bahwa kadar abu paling rendah untuk setiap perlakuan briket yaitu $13,1 \%$. Sehingga ditinjau dari kadar abu, briket-briket ini belum memenuhi syarat.

\section{Analisis Kandungan Fixed Carbon}

Pada bagian ini, akan dibahas pengaruh suhu pengarangan dan waktu pengarangan terhadap kandungan fixed carbon briket.

\section{Analisis Pengaruh Suhu Dan Waktu Pengarangan terhadap Kandungan Fixed Carbon}

Selain pengaruh suhu pengarangan, waktu pengarangan juga mempengaruhi kandungan fixed carbon briket. Pengaruh waktu pengarangan terhadap kandungan fixed carbon pada berbagai suhu yaitu $350^{\circ} \mathrm{C}, 400^{\circ} \mathrm{C}, 450^{\circ} \mathrm{C}$ dan $500^{\circ} \mathrm{C}$ dapat dilihat pada Gambar 4

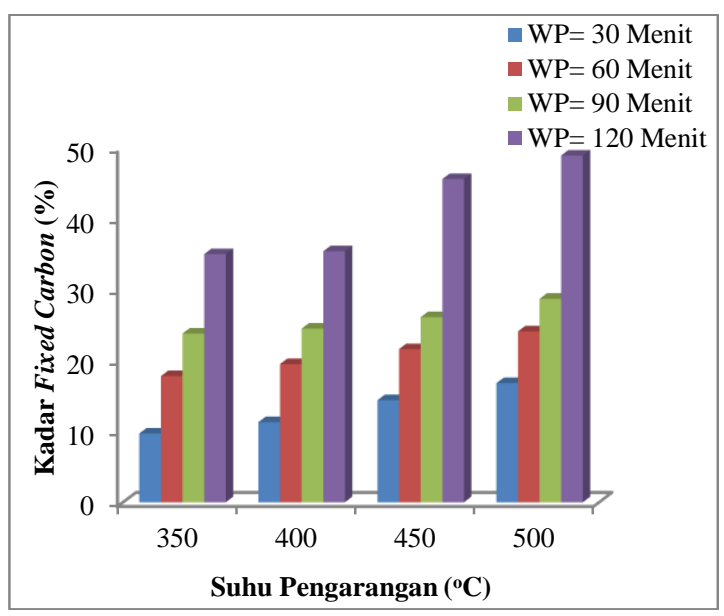

Gambar 4. Pengaruh Suhu dan Waktu Pengarangan terhadap Kadar Fixed Carbon

Dari Gambar 4 terlihat bahwa kandungan fixed carbon pada briket pada masing-masing mengalami kenaikan seiring dengan bertambahnya waktu pengarangan. Semakin tinggi kadar karbon terikat maka semakin baik pula kualitas briket yang dihasilkan, karena kadar karbon terikat yang tinggi akan menghasilkan briket yang minim asap pada saat pemakaian. Begitu pula sebaliknya jika kadar karbon terikatnya rendah maka kualitas briket semakin jelek. Selain itu, semakin tinggi kadar karbon terikat maka nilai kalor yang dihasilkan akan semakin tinggi [17]. Konsentrasi perekat dan tekanan pengempaan mempengaruhi kualitas briket seperti kadar air dan senyawa volatil. Kandungan kadar air dan senyawa volatil itulah yang mempengaruhi kandungan fixed carbon pada 
suatu briket. Dari persamaan diketahui kadar air, kadar abu dan kadar senyawa volatil dapat dipengaruhi dari perlakuan tekanan pengempaan dan konsentrasi perekat.

Kadar fixed carbon briket tertinggi mencapai angka $48,9 \%$ yaitu pada briket dengan suhu pengarangan $500^{\circ} \mathrm{C}$ pada waktu pengarangan 120 menit, sedangkan kandungan fixed carbon terendah pada briket adalah $9,7 \%$ yaitu pada briket dengan perlakuan suhu pengarangan $350^{\circ} \mathrm{C}$ dengan waktu 30 menit, kandungan fixed carbon briket sangat rendah jika dibandingkan dengan standar. Standar kandungan fixed carbon briket Indonesia adalah 77\%. Fixed carbon adalah fraksi karbon yang terdapat didalam arang selain fraksi air, senyawa volatil, dan abu. Kandungan fixed carbon mempengaruhi nilai kalor sebuah briket. Semakin tinggi kandungan fixed carbon maka semakin tinggi pula nilai kalor sebuah briket [22]. Oleh karena itu, briket diharapkan memiliki kandungan fixed carbon yang tinggi.

\section{Analisis Nilai Kalor}

Pada gambar 5 dapat dilihat nilai kalor pada briket dari berbagai suhu dan waktu pengarangan pada proses pengarangan.

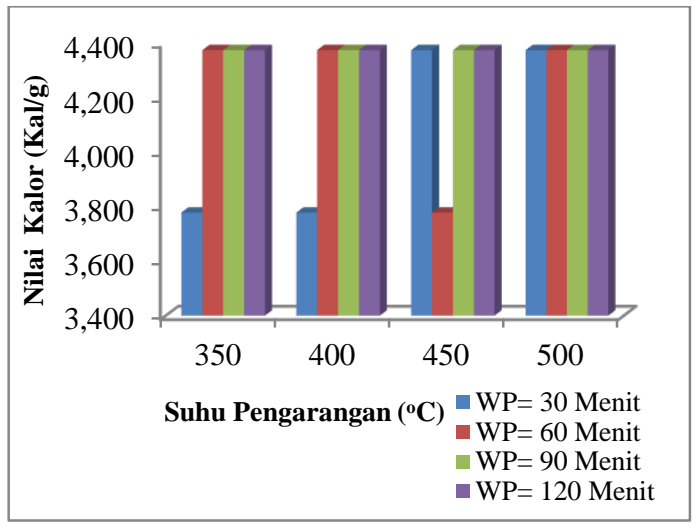

Gambar 5. Hubungan Nilai Kalor terhadap Suhu dan Waktu Pengarangan.

Gambar 5 memperlihatkan bahwa nilai kalor tertinggi adalah $4.374 \mathrm{kal} / \mathrm{kg}$ yaitu pada briket yang dikarbonisasi dengan waktu pengarangan 30 menit $450^{\circ} \mathrm{C}$ dan $500^{\circ} \mathrm{C}$ dan 60 menit, 90 menit dan 120 menit pada suhu pengarangan $350{ }^{\circ} \mathrm{C}, 400{ }^{\circ} \mathrm{C}$, $450^{\circ} \mathrm{C}$ dan $500^{\circ} \mathrm{C}$. Nilai kalor terendah dimiliki oleh briket yang dikarbonisasi dengan proses pengarangan suhu $450^{\circ} \mathrm{C}$ dengan waktu pengarangan 60 menit,dan dikempa dengan tekanan $105 \mathrm{~kg} / \mathrm{cm}^{2}$. Dilihat dari tabel lampiran A, suhu pengarangan tidak secara khusus atau mutlak mempengaruhi nilai kalor sebuah briket. Hal serupa juga berlaku untuk tekanan pengempaan dan proses pengarangan. Ketiga faktor tersebut dengan variasi masing-masing turut mempengaruhi nilai kalor pada briket.

Dapat dilihat bahwa jika kandungan fixed carbon briket tinggi maka nilai kalor briket juga meningkat. Seperti yang telah dijelaskan sebelumnya, nilai fixed carbon berpengaruh terhadap nilai kalor briket. Nilai kalor briket merupakan indikasi energi yang tersimpan dalam briket untuk digunakan sebagai bahan bakar [6]. Semakin tinggi nilai kalor, maka semakin tinggi pula energi yang tersimpan di dalamnya.

Nilai kalor merupakan parameter terpenting yang menentukan kualitas briket. Namun, nilai kalor yang didapat pada penelitian ini masih jauh dari standar SNI yakni $5.000 \mathrm{kal} / \mathrm{g}$ [22]. Oleh karena itu, briket yang dihasilkan belum dapat dikatakan sebagai briket yang baik.

\section{Analisis Sifat Fisik Briket}

Briket merupakan salah satu sumber energi alternatif yang penting. Namun sebelum digunakan, terlebih dahulu perlu dilakukan pengujianuntuk mengetahui kualitas briket yang dihasilkan. Analisa kualitas briket yang dihasilkan adalah untuk mengetahui pengaruh variasi suhu pengarangan briket terhadap kadar air, kadar senyawa volatil, kadar abu, kandungan fixed carbon dan nilai kalor briket serta pengaruh waktu pengarangan briket terhadap kadar air, kadar senyawa volatil, kadar abu, kandungan fixed carbon dan nilai kalor briket

Selain analisis kualitas dan kandungan briket, sifat fisik briket juga tidak kalah penting untuk dilakukan dalam menentukan baik atau tidaknya sebuah briket. Briket diharapkan memiliki sifat fisik antara lain tidak meninggalkan warna hitam jika dipegang, tidak berjamur, kuat, dan saling merekat satu sama lain agar tidak mudah hancur $[14,23]$. Briket merupakan arang yang dibentuk dengan bantuan alat mekanik sehingga mudah dalam proses penyimpanan ataupun transportasi $[20,21]$.

Kulit ubi kayu mengandung karbohidrat dan serat yang tinggi sehingga diyakini mampu menjadi perekat dalam pembuatan briket. Namun, berdasarkan hasil yang diperoleh perekat kulit ubi kayu tidak berfungsi sebagai perekat yang baik. Hal ini kemungkinan karena kandungan tanin dalam kulit ubi kayu yang tidak ada. Selain itu, konsentrasi perekat kulit ubi kayu terhadap berat 
sampel yaitu 20\%. Pada penelitian ini, sifat fisik briket tidak memenuhi standar karena briket dengan perekat kulit ubi kayu tidak menghasilkan briket yang cukup merekat sehingga mudah hancur dan tidak kuat. Pada saat briket akan dicetak dan dikeringkan di oven, beberapa briket hancur ketika disentuh karena sangat lunak. Ketika dijatuhkan dari ketinggian \pm 1 meter, briket hancur seketika. Baik briket yang di arangkan dengan suhu $350^{\circ} \mathrm{C}$, $400{ }^{\circ} \mathrm{C}, 450^{\circ} \mathrm{C}$ dan $500^{\circ} \mathrm{C}$ pada waktu 30 menit, 60 menit, 90 menit dan 120 menit. Oleh karena itu, perekat kulit ubi kayu tidak dapat digunakan sebagai perekat dalam pembuatan briket.

\section{Kesimpulan}

Kesimpulan yang dapat diambil dari penelitian ini adalah:

1. Kulit ubi kayu tidak dapat digunakan sebagai perekat dalam pembuatan briket karena briket yang dihasilkan bersifat lunak dan mudah hancur disebabkan karena kandungan karbohidrat dalam kulit ubi kayu sangat sedikit dan tidak mengandung tanin sebagai salah satu syarat sebagai perekat.

2. Kadar air briket terendah yaitu $17,8 \%$ pada suhu pengarangan $500{ }^{\circ} \mathrm{C}$ waktu pengarangan 120 menit dengan standar kadar air briket Indonesia adalah 7,57\%.

3. Kadar senyawa volatil briket terendah yaitu $20,26 \%$, kadar senyawa volatil briket ini tidak sesuai dengan standar briket Indonesia yaitu $15 \%$.

\section{Daftar Pustaka}

[1] A. Saurabh, Carbonization of Eucalyptus Wood and Characterization of The Properties of Chars for Application In Metallurgy, Master of Technology Department of Metallurgical \& Materials Engineering National Institute of Technology Rourkela, Orissa. (2013-2014).

[2] ASTM, Standard Test method for moisture in the analysis sample of coal and coke, American Society for Testing and Materials, USA, (2003) ASTM D3173 - 03.

[3] ASTM, Standard test method for ash in the analysis sample of coal and coke from coal,American Society for Testing and Materials, USA, (2004) ASTM D3174 - 04.

[4] ASTM, Standard test method for gross calorific value of coal and coke by microprocessor controlled isoperibol calorimeters, American Society for Testing and Materials, USA, (1997) ASTM D1989 97.

[5] ASTM, Standard test method for volatile matter in the analysis sample of coal and coke, American Society for Testing and Materials, USA, (2007) ASTM D3175 - 07.

[6] ASTM, Standard practice for proximate analysis of coal and coke, American Society for Testing and Materials, USA, (2007) ASTM D3172 - 07a.

[7] B.V. R. Y. P. Khandetod., A. G. Mohod dan N. S. Sonawane, Characterization Of Selected Raw Biomass For Briquetting, Ind. Journal. Sci. Res. and Tech, (2014) Vol 2. No 4. ISSN:-2321-9262, p. 40-44.

[8] D. Patabang, Karakteristik Termal Briket Arang Sekam Padi Dengan Variasi Bahan Perekat, Jurnal Teknik Mesin, Fakultas Teknik, Universitas Tadulako, (2012) Vol 3 Nomor 2.

[9] E. J. Prasetyo, Perbandingan Penggunaan Arang Aktif Kulit Kacang Tanah-Reaktor Biosan Filter dan Mn Zeloit-Reaktor Biosan Filter untuk menurunkan kadar COD DAN BOD dalam air limbah industri farmasi, Skripsi, Jurusan Kimia, Fakultas MIPA, Universitas Negeri Semarang, (2013).

[10] E. A. Emerhi, Physical and Combustion Properties of Briquettes Produced from Sawdust of Three Hardwood Species and Different Organic Binders, Journal, Advanced in Applied Science Research, (2014) Vol 2, No 6, p. 236-267.

[11] G. W. Bestari, Pegaruh Konsentrasi Perekat Daun Jambu Mete dan Tekanan Pengompakan Dalam Pembuatan Briket dari Sekam Padi Dan Ketaman Kayu,Skripsi, Jurusan Teknik Kimia, Fakultas Teknik, Universitas Sumatera Utara, Medan, (2015).

[12] K. N. Wahyusi, R. Dewati,R. P. Regilia dan T. Kharisma, Briket Arang Kulit Kacang Tanah Dengan Proses Karbonisasi, Skripsi, Jurusan Teknik Kimia, Fakultas Teknologi Industri, UPN, Surabaya, (2012).

[13] K. Elly, Pemanfaatan Cangkang Kelapa Sawit Sebagai Arang Aktif, Jurnal Penelitian Ilmu Teknik, Vol 8, No 2, (2008) P. 96-103.

[14] M. Destiana, Pemanfaatan Tepung Kulit Singkong Sebagai Bahan Subsitusi Pembuatan Mie Basah ditinjau Dari Elastisitas dan Daya Terima, Laporan, Program Studi DIII Gizi, Fakultas Ilmu Kesehatan, Universitas Muhammadiyah Surakarta, (2013). 
[15] M. Luthfi dan Muhammad, Pengaruh Variasi Komposisi Campuran Pada Biobriket Kulit Mete Dan Sekam Padi Terhadap Laju Pembakaran, Rotasi Jurnal Teknik Mesin, (2012) Vol 14, No 4, p. 15-22.

[16] M. Stephen, J. K. F. Mensah dan N. A. Darkwa, Evaluation of Fuel Properties of Six Tropical Hardwood Timber Species for Briquettes, Journal of Sustainable Bioenergy Systems, (2014) Vol 4, p. 1-9.

[17] N. J. Rexanindita, Karakteristik Termal Briket Arang Ampas Tebu dengan Variasi Bahan Perekat Lumpur Lapindo, Skripsi, Jurusan Teknik Mesin, Fakultas Teknik, Universitas Jember, (2000).

[18] Oladeji dan C. C. Enweremadu, A Comparison of the Use of Pyrolysis Oils in Diesel Engine,Journal, Energy and Power Engineering, (2013) Vol 5, p. 350-355.

[19] O. I. M. Ogbu dan C. Ejikeme, Comparative Analyses Of Densities And Calorific Values Of Wood And Briquettes Samples Prepared At Moderate Pressure And Ambient Temperature, International Journal of Plant, Animal adn Enviromental Sciences, (2012) Vol 2, ISSN 2231- 4490.

[20] O. Sitompul, Pengaruh variasi perekat pada pembuatan biobriket dari campuran ampas tebu dan tempurung kelapa, Skripsi, Jurusan Teknik Kimia, Politeknik Negeri Sriwijaya, (2014).

[21] R. Ani, Pemanfaatan Limbah Kulit Ubi Kayu dan Kulit Nanas pada Produksi Bioetanol menggunakan Aspergillus niger,Skripsi, Jurusan Biologi, Fakultas Matematika dan Ilmu Pengetahuan Alam, Universitas Sebelas Maret, Surakarta, (2010).

[23] S . Siahaan, M. Hutapea dan R. Hasibuan, Penentuan Kondisi Optimum Suhu dan Waktu Karbonisasi pada Pembuatan Arang dari Sekam Padi, Jurnal Teknik Kimia USU, (2013) Volume 2, p. 26-30.

[26] Winaya, Co-Firing Sistem Fluized Bed Berbahan Bakar Batubara dan Ampas Tebu". Jurnal Ilmiah Teknik Mesin Udayana, Bali, (2010) Vol.4, No.2, p.180188.

[27] Zaenal, Mempelajari Daya Bakar Briket Kulit Kacang Tanah Berdasarkan Perbedaan Densitas, Skripsi, Program Study Keteknikan Pertanian, Jurusan Teknik Pertanian, Fakultas Pertanian. Universitas Hasanuddin, Makasar, (2012). 